\title{
Epidemiological Surveillance of Amyotrophic Lateral Sclerosis in Saguenay Region
}

\author{
Émilie Lareau-Trudel, Élizabeth Fortin, Marianne Gauthier, Sarah Lavoie, \\ Érika Morissette, Jean Mathieu
}

\begin{abstract}
Objectives: The Neuromuscular Registry of Saguenay-Lac-Saint-Jean (SLSJ), Québec, Canada was established for epidemiological surveillance of neuromuscular disorders including amyotrophic lateral sclerosis (ALS). The objectives of this study are to analyze the ALS clinical characteristics of the SLSJ population and to determine the incidence rate over time by five year periods since 1985. Methods: The Registry was validated by a review of the medical records maintained at the CSSS de Chicoutimi, the regional university hospital and, by the estimation of the number of hospitalizations for ALS patients using the Quebec Hospital inpatient database (MED-ECHO). Results: A total of 109 patients were included. Overall, the clinical features of ALS observed in SLSJ population are similar to those described in the literature. We observed a significant increase in the incidence rate of ALS during the 2005-2009 period compared with the previous periods. This is due to a significant increase in the incidence rate among the $\geq 65$ years old group, from 4.68 per 100,000 persons/year (CI 95\% 2.88-6.48) during 1985-2004 period to 12.22 (CI 95\% 7.43-17.02) during 20052009 period. Conclusion: Given the small size of the SLSJ population, a longer observation period will be needed to confirm a new steady state incidence of ALS in this region.
\end{abstract}

RÉSUMÉ: Surveillance épidémiologique de la sclérose latérale amyotrophique au Saguenay. Objectifs : Le Registre neuromusculaire du Saguenay-Lac-Saint-Jean (SLSJ) au Québec, Canada, a été créé pour effectuer la surveillance épidémiologique des maladies neuromusculaires dont la sclérose latérale amyotrophique (SLA). Les objectifs de cette étude étaient d'analyser les caractéristiques cliniques de la SLA dans la population du SLSJ et de déterminer le taux d'incidence de la maladie par périodes de 5 ans à partir de 1985. Méthode : Le registre a été validé au moyen d'une revue des dossiers médicaux conservés au CSSS de Chicoutimi, l'hôpital universitaire régional, et du nombre d'hospitalisations de patients atteints de SLA selon la base de données de patients hospitalisés au Québec (MED-ECHO). Résultats : Cent neuf patients ont été inclus dans l'étude. Globalement, les manifestations cliniques de la SLA observées dans la population du SLSJ sont semblables à celles décrites dans la littérature. Nous avons observé une augmentation significative du taux d'incidence de la SLA pendant la période 2005-2009 comparé à celui des périodes antérieures. Ceci est dû à une augmentation significative du taux d'incidence dans le groupe des gens âgés de 65 ans et plus, soit de 4,68 par 100000 personnes/année (IC à $95 \%$ 2,88 à 6,48) pendant la période de 1985 à 2004 à 12,22 (IC à 95\% 7,43 à 17,02) pendant la période 2005 à 2009. Conclusion : Étant donné la petite taille de la population du SLSJ, une période d'observation plus longue sera nécessaire pour déterminer s'il s'agit d'une augmentation stable de l'incidence de la SLA dans cette région.

Can J Neurol Sci. 2013; 40: 705-709

Amyotrophic lateral sclerosis (ALS), the most frequent of the motor neuron diseases, is a progressive and invariably fatal neuromuscular disease that affects upper and lower motor neurons in the cortex, brainstem and spinal cord. The annual incidence of ALS ranges from 1 to 2 per 100000 population and only small variations are reported between different countries. The incidence varies with age, with a higher rate between the age of 55 and 75 years $^{1-4}$.

In recent years, some studies reported an increase incidence or mortality from ALS $\mathrm{S}^{1-3,5-13}$. The assumptions to explain this phenomenon were: environmental factors, increasing ascertainment in making the diagnosis, and increase in life expectancy ${ }^{14}$.

The geographic and sanitary characteristics specific of the Saguenay-Lac-Saint-Jean (SLSJ) region (Québec, Canada) allowed an almost complete ascertainment of patients with neuromuscular diseases and a full population-based survey of these disorders. In this region, all patients with ALS are followed at the Neuromuscular Clinic (NMC) since it was created in 1981.

The objectives of the study are 1) to analyze the ALS clinical characteristics of the SLSJ population, 2) to determine the incidence rate over time by five year periods since 1985 and, 3) to validate the Neuromuscular Registry.

From the Faculty of Medicine and Health Sciences (ELT, EF, MG, SL, EM, JM), Sherbrooke University; Neuromuscular Clinic (JM), Jonquiere Hospital, Quebec, Canada.

Received January 11, 2013. Final Revisions Submitted March 6, 2013 Correspondence to: Jean Mathieu, Neuromuscular Clinic, Carrefour de Santé de Jonquière, 2230 rue de l'Hôpital, Jonquière, Québec, G7X 7X2, Canada.

Email: jmathieu50@videotron.ca. 


\section{METHODS}

Structure of health services in SLSJ region. The SLSJ region is a well defined and relatively isolated territory of $98768 \mathrm{~km}^{2}$ in the north-eastern part of the Province of Quebec, Canada. This region has grown to a current population of 273,264 at the 2009 census (Institut de la Statistique du Québec). The Health and Social Services network of the SLSJ region includes seven public hospitals including a regional reference university hospital located at Saguenay (CSSS de Chicoutimi). This network provides the whole range of general and specialized services aimed at the SLSJ population: prevention, evaluation, diagnosis, treatment, rehabilitation, support, and residential care services. Rehabilitation services for all the region are coordinated by the Regional Rehabilitation Center located in Jonquière where the NMC is established. Over the last 30 years, the whole range of specialized services for patients with neuromuscular disorders were provided in this region by the NMC. All the individuals affected by ALS and living in the SLSJ region are registered at the NMC and followed on a three month basis, therefore limiting missing data and loss to follow-up.

\section{The Neuromuscular Registry}

Demographic and clinical data of all patients with neuromuscular disorders, including ALS patients, are stored on a confidential computer database maintained at the NMC since 1983. The definitions and collection procedures of the registry have not changed since its implementation. All patients who attended our ALS outpatient clinic in the period between 1985 and 2009 were included. All patients retrospectively met the revised El Escorial criteria for probable or definite ALS at the time of onset or within the observation period ${ }^{15}$. Patients with possible or suspected ALS were excluded from the analysis. For the present study, the data extracted from the registry included date of birth, gender, date of diagnosis, clinical pattern at the onset of symptoms and date of death.

\section{Validation of the Neuromuscular Registry}

Completeness of the Neuromuscular Registry was validated by a revision of the medical records maintained at the Centre de Santé et des Services Sociaux (CSSS) of Chicoutimi, the regional university hospital. Charts with a final diagnosis of ALS or motor neuron disease from 1985 to 2009 were reviewed.

With the support of the Agence de la Santé et des Services Sociaux (ASSS) of SLSJ, we used the Quebec Hospital inpatient database (MED-ECHO) to estimate the number of hospitalizations of patients with a diagnosis of ALS or motor neuron disease and the trend in incidence of ALS for the period 1990 to 2009. The MED-ECHO database can be used to estimate inhospital length of stay and number of hospitalizations both accurately and reliably ${ }^{16}$.

\section{Statistical analysis}

T-test or Mann-Whitney U tests were used to compare the mean or median age at onset or delay between the age at onset and the age at diagnosis between gender, age groups or periods of observation. Chi-square tests were used to compare distribution of clinical pattern at onset between gender, periods of observation and survival periods. The Kruskal-Wallis test was used to analyse median survival among age groups. The Spearman correlation coefficient $\left(r_{s}\right)$ was used to study the relation between the delay before age at onset and the age at diagnosis and the survival duration. SLSJ population numbers over the 25-year interval 1985-2009 were abstracted from the Statistics Canada censuses. Based on date of ALS diagnosis, yearly incident cases were used to calculate crude and agespecific incidence rates per 100,000 person-years. The $95 \%$ confidence intervals (CI) for incidence rates were calculated using the normal approximation. To study changes in incidence of ALS over time, we considered five time periods: 19851989,1990-1994, 1995-1999, 2000-2004 and 2005-2009. A Pvalue less than 0.05 was considered significant. Statistical analyses were performed using the SPSS statistical software package [IBM SPSS Statistics, version19, 2010].

\section{RESULTS}

\section{Patients}

A total of 109 patients with ALS were included in the present study, 97 (89\%) of them were registered in the Neuromuscular Registry. Twelve (12) additional patients with El Escorial criteria for probable or definite ALS were identified during the revision of the medical records at the CSSS de Chicoutimi. These 12 cases were distributed equally over the 25-year period of observation and most of them were diagnosed late in the course of the disease and died before referral to the NMC. Among the 109 patients, 54 $(49.5 \%)$ were male and 55 females.

\section{Age at onset}

The age of onset was found in 96 (88\%) records (49 men, 47 women). The mean age at onset was $62.8 \pm 12.86$ years. Women were significantly older at onset $(65.6 \pm 12.1$ years $)$ than men $(59.8 \pm 13.0$ years $)(p=0.026)$.

\section{Delay between age at onset and age at diagnosis}

The age at diagnosis of ALS was known for 103 patients. The delay between age at onset and age at diagnosis was found in 94 (86\%) records (47 men, 47 women). The median delay was 6.97 months (range 0 to 114.9). The delay was similar between men and women; it was 6.3 months for men and 7.5 for women $(\mathrm{p}=0.098)$.

\section{Clinical patterns at onset}

Data about symptoms at onset were found in 102 (94\%) cases. The two most frequent patterns at onset were: limb-onset in $59(58 \%)$ patients and bulbar symptoms in 34 (33\%). Other presentations were: mixed symptoms in five patients and upper motor neuron onset in four patients. The clinical pattern was similar between men and women $(\mathrm{p}=0.56)$.

Regarding diseases that may be associated with the diagnosis of ALS, some diseases were found more frequently in our data. Of the 109 patients included in the study, we found 31 cases of hypertension $(28.4 \%), 9$ cases of hypothyroidism (8.3\%), 27 cases of hypercholesterolemia $(24.8 \%)$ and 11 cases of depression or anxiety (10.1\%). Among these 109 patients, only one patient had a possible familial ALS with a suspected affected sister living outside the region. 


\section{Survival time from onset of symptoms}

Analyses of the survival time from the onset of symptoms were made for 87 ( 40 men, 47 women) of the 109 cases. The median survival time for the entire group was 2.1 years with a range from 0.4 to 21.9 years. Median survival time was similar for both genders: 2.3 years (range 0.4 to 15.0 ) for men and 2.1 years (range 0.4 to 21.9 ) for women ( $p=0.855$ ).

An analysis of the duration of survival performed in three (3) age groups shows a significant decrease in survival time with age: 25 to 44 years group $(\mathrm{n}=8)$, median survival of 3.8 years (range 1.5 to 15.0$), 45$ to 64 years group $(\mathrm{n}=37)$, median survival of 2.7 years (range 0.8 to 21.9 ) and $\geq 65$ years group (n $=42$ ), median survival of 1.7 years (range 0.4 to 13.0$)(\mathrm{p}=$ $0.001)$.

The survival time from the onset of symptoms was evaluated according to the initial presentation of the disease (limb onset, bulbar and the mixed form) for 86 subjects. The median survival time was 2.3 years (range 0.4 to 15.0 ) for limb onset form, 2.3 years (range 0.4 to 21.9) for bulbar form and 2.03 years (range 1.3 to 3.1$)$ for the mixed form $(\mathrm{p}=0.441)$.

We examined whether the time between onset of symptoms and diagnosis is a prognostic factor for survival time. We observed a significant correlation $\left(\mathrm{r}_{\mathrm{s}}=0.383, \mathrm{p}<0.0001\right)$ between a shorter time between the first symptoms and diagnosis and a decreased survival time.

\section{Incidence rates per five year periods from 1985 to 2009}

Date of diagnosis was known for 107 patients and incidence rates of ALS in the SLSJ region were calculated by five year periods between 1985 and 2009. For the first 20 years of observation, the incidence rates were stable and ranged from 0.91 to 1.37 new cases per 100,000 people per year. For the 2005 to 2009 period, we observed a significant increase in the incidence rate to 3.01 new cases per 100,000 people per year (Table 1).

\section{Incidence rates according to age groups and gender}

By dividing the cohort into three (3) age groups at diagnosis (25-44 years, 45-64 years and $\geq 65$ years), we found a statistically significant increase in incidence rates with
Table 1: Incidence rates of ALS in SLSJ region by 5 years period

\begin{tabular}{cccc}
\hline Years & $\mathbf{N}$ & Incidence rate & $\mathbf{C l ~ 9 5 \%}$ \\
$1985-1989$ & 13 & 0.91 & $0.42-1.41$ \\
$1990-1994$ & 15 & 1.05 & $0.52-1.58$ \\
$1995-1999$ & 19 & 1.33 & $0.73-1.92$ \\
$2000-2004$ & 19 & 1.37 & $0.75-1.98$ \\
$2005-2009$ & 41 & 3.01 & $2.09-3.93$ \\
\hline
\end{tabular}

increasing age. In the 25-44 years group $(n=11)$, the incidence rate was 0.51 (CI 0.21-0.82); in the 45-64 years group $(n=40)$, the incidence was 2.39 (CI 1.65-3.12) and, in the $\geq 65$ years group $(n=52)$, the incidence was 6.84 (CI 4.98-8.70).

There were no significant difference in incidence rate between men and women. In the men group $(n=54)$, the incidence rate was 1.54 (CI 1.13-1.95) and, in the women group $(\mathrm{n}=49)$, the incidence was 1.38 (CI 1.00-1.77).

\section{Comparisons between 1985-2004 and 2005-2009 periods}

In order to understand the increased incidence of ALS during the 2005-2009 period, we regrouped patients in two time periods (1985-2004 and 2005-2009) to proceed to comparisons between these two groups according to age at onset, age at death, survival time, clinical patterns at onset and incidence rate by age groups.

The mean age of onset was significantly higher in patients in the 2005-2009 group (66.41 years \pm 12.07$)$ than patients in the 1985-2004 group $(59.95$ years \pm 13.04$)(\mathrm{p}=0.016)$ and a significant higher age at death was also observed: the mean age of death for the 1985-2004 group was 63.4 years \pm 13.2 years and 69.6 years \pm 11.4 for the 2005-2009 group ( $\mathrm{p}=0.024)$.

The survival time after the onset of symptoms was similar during the two time periods: 2.5 years (range 0.41 to 21.9 ) for the 1985-2004 group and 1.81 years (range 0.42 to 5.99 ) for the 2005-2009 group $(\mathrm{p}=0.102)$. Clinical patterns at onset were similar in both groups $(\mathrm{p}=0.211)$ and in each gender $(\mathrm{p}=0.902)$.

Table 2: Comparison of incidence rates (per 100000 person-years) by age groups at diagnosis of ALS for the $1985-2004$ period and 2005-2009 period

Age groups at diagnosis of ALS 1985-2004

$2005-2009$

\begin{tabular}{|c|c|c|c|c|c|c|c|c|}
\hline & $\mathrm{N}$ & SLSJ Population* & Incidence rate & (Cl 95\%) & $\mathrm{N}$ & SLSJ population ${ }^{*}$ & Incidence rate & $(\mathrm{Cl} 95 \%)$ \\
\hline $0-24$ yrs & 0 & 103966 & 0 & - & 0 & 78315 & 0 & - \\
\hline $25-44$ yrs & 9 & 42517 & 0.5 & $(0.17-0.82)$ & 2 & 66345 & 0.6 & $(0.1-1.44)$ \\
\hline $45-64$ yrs & 27 & 90217 & 2.17 & $(1.35-2.99)$ & 12 & 87035 & 2.76 & $(1.20-4.32)$ \\
\hline$\geq 65$ yrs & 26 & 27792 & 4.68 & $(2.88-6.48)$ & 25 & 40905 & 12.22 & $(7.43-17.02)$ \\
\hline
\end{tabular}

* Mean SLSJ population according to 1986, 1991, 1996 and 2001 Statistics Canada censuses; $¥$ Mean SLSJ population according to 2006 Statistics

Canada census 
To calculate the age-specific incidence rates according to time periods 1985-2004 and 2005-2009, data on date of diagnosis and age at diagnosis were known for 101 patients. The incidence rates by age groups showed a significant increase for the period 2005-2009 in the elderly ( $\geq 65$ years), while the incidence rates remained stable for the other age groups between these two periods (Table 2).

\section{Comparison with the MED-ECHO database}

During the period from 1990 to 2009, 116 hospitalizations for patients with a diagnosis of ALS were recorded in the MEDECHO database for the SLSJ region. The Figure illustrates a clear increase in the number of hospitalizations for the years 2006, 2008 and 2009. Although many patients with ALS are never hospitalized in general hospitals, leading to an underestimation of the number of cases, and although the potential of misclassification due to coding rules, the clear increase of hospitalizations in recent years supports the significant increase of the incidence rate documented by the Neuromuscular Registry.

\section{DISCUSSION}

Overall, the clinical features of ALS and the survival time observed in SLSJ population are similar to those described in the literature ${ }^{17,18}$.

Our study shows a significant increase in the incidence rate in ALS in SLSJ region for the 2004-2009 period. This conclusion is supported by the increased number of hospitalizations of ALS patients recorded by the MED-ECHO database during the same time period. Increased incidence rate or mortality by ALS has already been described in other epidemiological studies published in the last decade. Other countries in which variation in incidence or mortality have been observed are Italy, Japan, New Zealand, Norway, Sweden and United States ${ }^{7-11,13}$. The phenomenon exposed in these studies is however more gradual over 15 years and was seen before the 2000s.

In addition, our study shows that the increase in the incidence rate is observed only in subjects $\geq 65$ years old, growing from 4.68 / 100000 person-years between 1985-2004 to 12.22 / 100 000 person-years between 2005-2009. This increase in the elderly population was also observed in Norway ${ }^{11}$. Increase in incidence rate cannot be explained by aging population since age adjusted incidence rates take into account the age distribution of the population growth during each time period. Improved medical care and greater access to neurology in the elderly over time could result in improved ALS diagnosis in patients older than 65 years. On the other hand, the resources in both clinical neurology and electromyography remained stable in the SLSJ region over the entire study period, excluding a better recognition of cases by neurologists as a potential cause of this increase in incidence rate.

We looked at several other parameters to better describe the cohort of patients with ALS between 2005-2009. Of these, clinical pattern at onset, sex ratio and length of survival do not seem to differ between the 1985-2004 period and the more recent period.

Other assumptions have been made to explain the increased incidence rate in ALS. One of these is the increase in life expectancy with increased co-morbidity and thus susceptibility to get ALS. Co-morbidities observed in our patient's records do not seem abnormally prevalent considering the average age of our population (Statistics Canada). The reliability of these data may be questioned, given the variability of these nonneurological data in the records of the NMC. Other risk factors for ALS are various environmental exposures including heavy

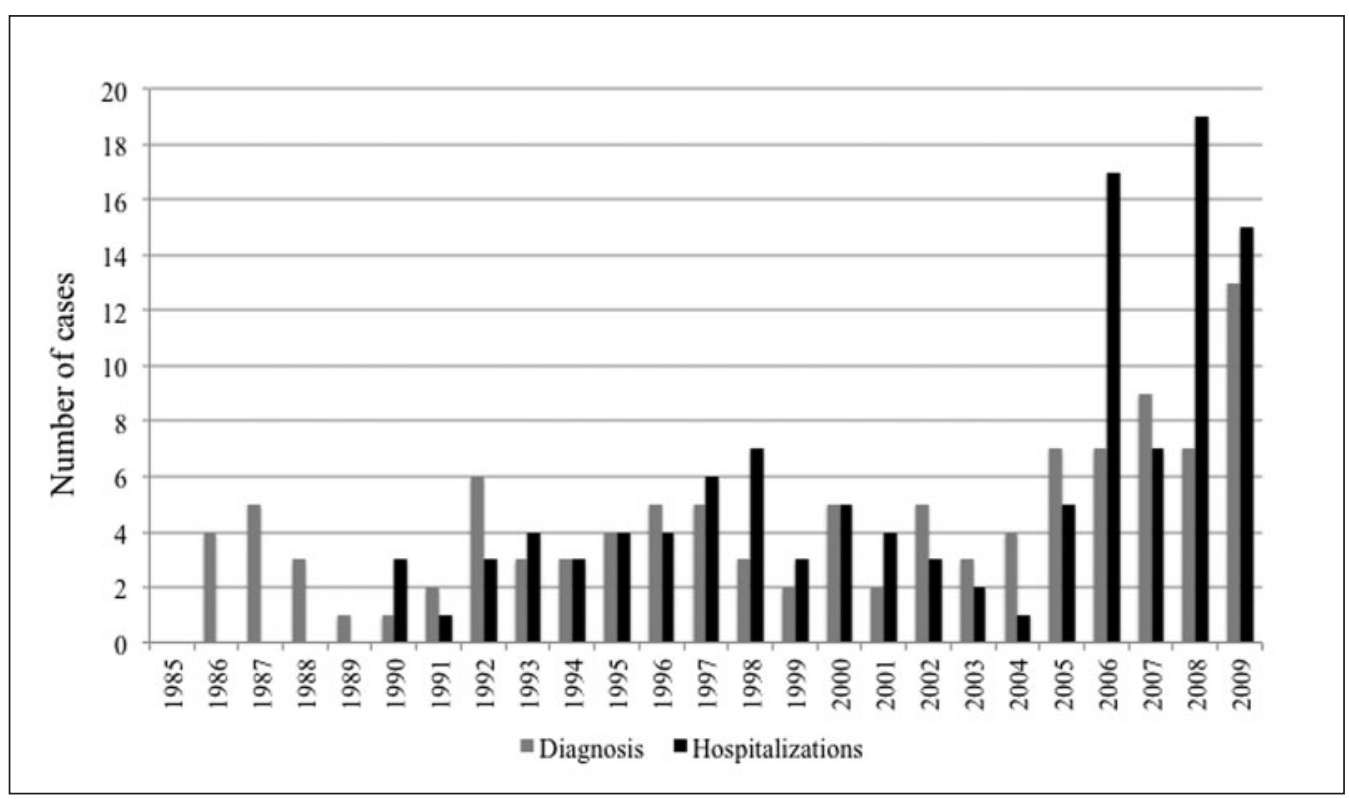

Figure: Number of new ALS diagnosis per year since 1985 and number of hospitalizations of patients with a diagnosis of ALS per year since 1990. 
metals or pesticide exposure, smoking, nutritional intake, physical activity, trauma and infectious agents ${ }^{19,20}$. Since we did not have enough information about environmental exposure in the patient's records, we cannot conclude on environmental contribution in the development of ALS in our study population. Some studies have reported higher mortality rates among women than men ${ }^{10,11}$, which could support an environmental hypothesis being in parallel with the entry of women in the workforce. Our results do not reflect this trend since women in our study are affected at a later age than men (mean 65.6 years vs 59.8 years for men).

The SLSJ population is well known for its high prevalence of certain genetic disorders as a result of a founder effect ${ }^{21}$. However, only one patient in our cohort has a suspected familial ALS. Although there are recent descriptions of ALS caused by genetic mutations in surprisingly high proportions of sporadic ALS patients, at this point in time, a genetic factor does not seem to explain the increased incidence of ALS in SLSJ region.

We looked at the prognostic factors of this disease. We observed a significant decrease of survival among elderly persons, as described in the literature ${ }^{22}$. A long delay between the onset of symptoms and diagnosis turns out to be a good prognosis: this observation is also reported in Europe ${ }^{22}$. Otherwise, an association between faster clinical progression and a bulbar onset has not been demonstrated in our study.

Finally, information obtained by the review of the medical records at the CSSS de Chicoutimi and data obtained from the MED-ECHO database support the validity of the Neuromuscular Registry. Only 12 (11\%) cases unknown from the registry were found in the records at the CSSS de Chicoutimi. According to the structure of health services and the geographic characteristics of the SLSJ region, case ascertainment is expected to be very high in this region but cannot be confirmed as complete or near complete as a confirmed population-based data source was not validated against. This may be interpreted as a limitation of this study. However, the Neuromuscular Registry should be maintained for epidemiological monitoring of neuromuscular diseases.

\section{Conclusion}

Given the small size of the SLSJ population, a longer observation period will be needed to confirm a new steady state incidence of ALS in this region. The Neuromuscular Registry is a valid tool for epidemiological monitoring of neuromuscular diseases.

\section{ACKNOWLEDGMENTS}

The authors thank Mr. Régis Couture and Dr. Mario Brisson from the Agence de la Santé et des Services Sociaux of SLSJ region for their support to give access to the MED-ECHO database.

\section{REFERENCES}

1. Gunnarson LG, Lindberg G, Söderfelt B, Axelson O. The mortality of motor neuron disease in Sweden. Arch Neurol. 1990;47:42-6.

2. Neilson S, Gunnarson LG, Robinson I. Rising mortality from motor neurone disease in Sweden 1961-1990: the relative role of increased population life expectancy and environmental factors. Acta Neurol Scand. 1994;90:150-9.

3. Neilson S, Robinson I, Nymoen EH. Longitudinal analysis of amyotrophic lateral sclerosis mortality in Norway, 1966-1989: evidence for a susceptible subpopulation. J Neurol Sci. 1994; 122:148-54.

4. McGuire V, Longstreth WT Jr, Koepsell TD, van Belle G. Incidence of amyotrophic lateral sclerosis in three counties in western Washington state. Neurology. 1996;47:571-3.

5. Neilson S, Robinson I, Hunter M. Longitudinal gompertzian analysis of ALS mortality in England and Wales, 1963-1989: estimates of susceptibility in the general population. Mech Aging Dev. 1992;64:201-16.

6. Lilienfeld DE, Chan E, Ehland J, et al. Rising mortality from motor neuron disease in the USA, 1962-84. Lancet. 1989;1:710-2.

7. Cima V, Logroscino G, D'Ascenzo C, et al. Epidemiology of ALS in Padova district, Italy, from 1992 to 2005. Eur J Neurol. 2009; 16:920-4.

8. Fang F, Valdimarsdóttir U, Bellocco R, et al. Amyotrophic lateral sclerosis in Sweden, 1991-2005. Arch Neurol. 2009;66:515-9.

9. Murphy M, Quinn S, Young J, Parkin P, Taylor B. Increasing incidence of ALS in Canterbury, New Zealand: a 22-year study. Neurology. 2008;71:1889-95.

10. Noonan CW, White MC, Thurman D, et al. Temporal and geographic variation in United States motor neuron disease mortality, 1969-1998, Neurology. 2005;64:1215-21.

11. Seljeseth YM, Vollset SE, Tysnes OB. Increasing mortality from amyotrophic lateral sclerosis in Norway. Neurology. 2000;55: 1262-6.

12. Forbes RB, Colville S, Parratt J, Swingler RJ. The incidence of motor neuron disease in Scotland. J Neurol. 2007;254:866-9.

13. Kihira T, Yoshida S, Kondo T, et al. An increase in ALS incidence on the Kii Peninsula, 1960-2009: a possible link to change in drinking water source. Amyotroph Lateral Scler. 2012;13(4): 347-50.

14. Pradat P-F, Attarian S, Camdessanché JP, et al. La recherche sur la SLA en 2009: Compte rendu du groupe bibliographique de la coordination des centres SLA. Rev Neurol. 2010;166:683-98.

15. Brooks BR, Miller RG, Swash M, Munsat TL; World Federation of Neurology Research Group on Motor Neuron Diseases. El Escorial revisited: revised criteria for the diagnosis of amyotrophic lateral sclerosis. Amyotroph Lateral Scler Other Motor Neuron Disord. 2000;1(5):293-9.

16. Monfared AA, Lelorier J. Accuracy and validity of using medical claims data to identify episodes of hospitalizations in patients with COPD. Pharmacoepidemiol Drug Saf. 2006;15(1):19-29.

17. Worms PM. The epidemiology of motor neuron diseases: a review of recent studies. J Neurol Sci. 2001;191:3-9.

18. Logroscino G, Traynor BJ, Hardiman O, et al. Incidence of amyotrophic lateral sclerosis in Europe. J Neurol Neurosurg Psychiatry. 2010;81:385-90.

19. Armon C. An evidence-based medicine approach to the evaluation of the role of exogenous risk factors in sporadic amyotrophic lateral sclerosis. Neuroepidemiology. 2003;22:217-28.

20. de Jong SW, Huisman MH, Sutedja NA, et al. Smoking, alcohol consumption, and the risk of amyotrophic lateral sclerosis: a population-based study. Am J Epidemiol. 2012;176(3):233-9.

21. Laberge AM, Michaud J, Richter A, et al. Population history and its impact on medical genetics in Quebec. Clin Genet. 2005:68: 287-301.

22. Soriani MH, Desnuelle C. Épidémiologie de la SLA. Rev Neurol. 2009;165:627-40. 